\title{
Reliability-based dynamical design of a singular structure for High Energy Physics experiments
}

\author{
Roberto Palma ${ }^{1}$, Jordi Torrent ${ }^{1}$, José Luis Pérez-Aparicio ${ }^{1}$, Lluis Ripoll ${ }^{1}$ \\ ${ }^{a}$ Department of Mechanical Engineering and Construction, Universitat Jaume I, Avda Sos Baynat, s/n, 12071 Castellón de la Plana (Spain), \\ e-mail: rpalma@uji.es \\ ${ }^{b}$ Enginyeria Mecànica i de la Construcciò Industrial, Universitat de Girona, (Spain) \\ ${ }^{c}$ Mecánica de Medios Continuos y Teoría de Estructuras, Universitat Politècnica de València, (Spain)
}

\begin{abstract}
The present work presents a comprehensive design and dynamic calculation of singular metallic structures, part of the Neutrino Experiment NEXT. The experiment uses an electroluminescent TPC chamber, a high-pressure 136Xe gas vessel enclosing the detector. A lead-block "castle" or containing box shields this vessel against external $\gamma$-rays from all directions; in spite of its heavy weight, the castle must be regularly open for the detector maintenance. Since the structures will be constructed at a middle-level seismic localization (Laboratorio Subterráneo Canfranc, Spain), the earthquake hazard must be taken into account. Vessel and castle are supported by a rigid frame, which must satisfy two requirements: i) the Spanish seismic standard, ii) for equipment protection, the detector maximum horizontal acceleration must be $<1\left[\mathrm{~m} / \mathrm{s}^{2}\right]$. This frame rests on special base isolators to decrease horizontal accelerations in case of an earthquake. Three dynamical calculations are conducted: i) a response spectrum analysis to comply with the standard, ii) five time-history analyses to calculate tolerances and, iii) a reliability-based approach using 1,000 timehistory responses to ensure satisfaction of the operating requirements. The final outcome is the design of a singular structure optimized for the NEXT experiment with a probability of failure against any standard earthquake of only $0.125 \%$
\end{abstract}

Keywords:

Singular metallic structure, Seismic devices, Response Spectrum Analysis, Time-history analysis, Reliability-based approach, High Energy Physics

\section{Introduction}

The Neutrino Experiment NEXT, is a High Energy Physics undertaking that searches the neutrinoless double beta decay detected by a TPC (Time Projection Chamber): a high-pressure 136Xe xenon gas vessel. The experiment is located at a middle-level seismic zone: the Laboratorio Subterráneo at Canfranc (LSC) in the Pyrenees mountains, close to the border between Spain and France. The vessel is shielded against external radiation inside a heavy structure (called "lead castle", see Figure 12); for more details refer to [1] and Section 3.

A metallic structure with seismic isolators to support the vessel and the lead castle is designed and calculated. This structure is composed of a very rigid rectangular frame with a vertical extension called "pedestal" to elevate the vessel, see Figure 12. The objective of the complete structure is to ensure the safety of the vessel, operating systems and personnel, and to guarantee the integrity of the experiment even in the case of an earthquake. The total cost, including all its elements, is a comparably moderate 145,000 euros.

But the cost of the vessel is high-more than two million euros-mostly due to the $100[\mathrm{~kg}]$ of xenon isotope $136 \mathrm{Xe}$ that amounts to 1.5 million euros; consequently, any damage in the vessel could provoke a gas escape and great economic loss. Since the structure is assembled at LSC, it must satisfy the Spanish seismic standard [2] as part of the project risk analysis. Due to operating requirements of the electronics, gas system, electric installation and other equipment (see Figure 12 top), this structure has to guarantee that the detector maximum horizontal acceleration $a_{H m x}$ at the vessel intakes is lower than $1\left[\mathrm{~m} / \mathrm{s}^{2}\right]$.

The structural set is considered singular for several reasons: first, its elements combine beams with steel 


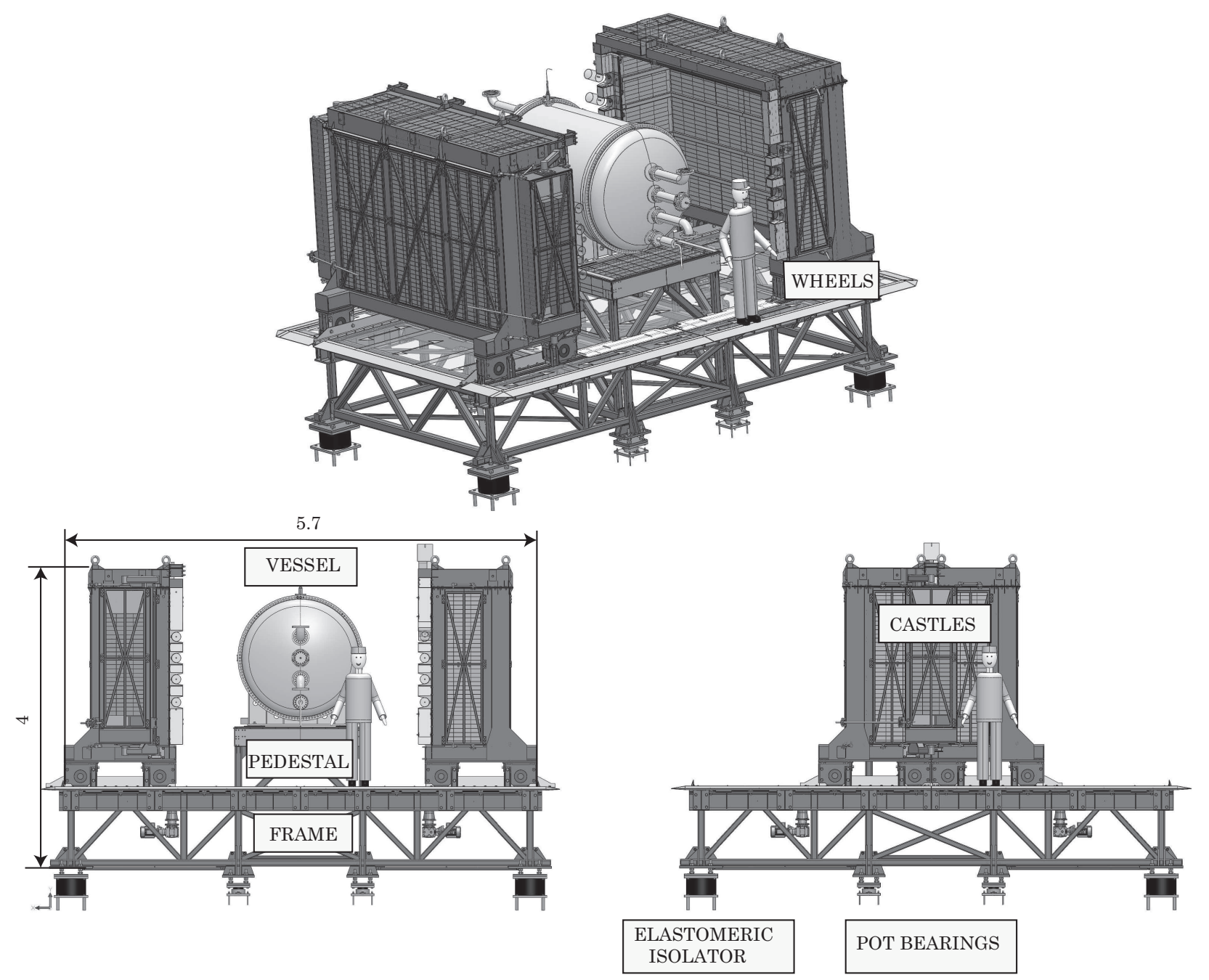

Figure 1: Three-dimensional view of the singular NEXT structure (top). Front views of open (bottom-left, for maintenance) and closed (bottomright, for operation) configurations. Structure composed of frame, pedestal, lead castle, vessel and seismic isolators. Dimensions in [m].

tubular close and open sections, and several steel and stainless steel large sheets. Second, the most important loads are gravitational from the castle, constructed in two symmetric parts that periodically must be opened for vessel maintenance; consequently, several different load distributions on the frame have to be considered. Third, the whole structure is of high stiffness to prevent detrimental displacements in the vessel and to guarantee the watertight closure of the castle. Finally and due to the seismic nature of the design, the frame is supported by two types of base isolators, see again the Figure 12, increasing the difficulty of the calculations.

The base isolation technology, [3], is in construction one of the most advanced protections against earthquakes that contain critical devices such as computer servers [4], electronic equipments [5, 6], precision machinery [7], etc. According to [8], the two main challenges in the design of structures with seismic isolation are the consideration of the variability of ground motions, see [9], and the non-linear response of the isolators. For these reasons, reliability-based designs have gained interest in the structural engineering community, for example see [8] and [10].

The main objective of the present work is the design and calculation of the singular structures, considering the seismic activity at the LSC. From the calculation point of view, the Finite Element (FE) method is used to model the full structure with a modal and two dynamic approaches. 


\section{NEXT experiment and seismicity at LSC}

Neutrinoless double beta decay is a hypothetical nuclear transition in which two neutrons undergo beta decay simultaneously and without the emission of neutrinos. This experiment has an important scientific interest: an unambiguous observation would establish that neutrinos are Majorana particles, or truly neutral particles identical to their antiparticles. Then, that the total lepton number is not a conserved quantity would be proven.

For a proper functioning of the experiment, two radiation sources must be prevented as much as possible. The first is the background radiation of the universe that is eliminated by locating the experiment at the underground LSC, with more than $1[\mathrm{~km}]$ of limestone on top of it. The second source is due to the ubiquitous $\gamma$-rays, and it is shielded by the lead castle and massive electrolytic copper plates inside the vessel.

According to the Spanish standard NCSE-02 [2], the seismicity around Canfranc is middle level: the basic seismic acceleration is $a_{b}=0.07 \mathrm{~g}$, where $g$ is the acceleration of gravity. The contribution coefficient, dependent on the type of soil in the area, is $K=1$. Since $a_{b}>0.04 g$, the application of NCSE-02 is mandatory.

In order to perform a seismic analysis, the working acceleration $a_{c}$ must be estimated. This magnitude depends on a dimensionless coefficient of risk and on the geotechnical characteristics of the foundation soil. Taking into account that the structure is singular and that the ground is composed of highly fractured silicon rocks, the result is $a_{c}=0.095 \mathrm{~g}$.

Since real structures are neither perfectly rigid (zero period) nor perfectly flexible (infinite period, zero horizontal acceleration $a_{H}$ ), a seismic design that quantifies the effects of the dynamical response is studied in the following sections. For this purpose, three methodologies are applied: Response Spectrum Analysis (RSA), dynamic Time-History (TH) and Reliability-based Design (RBD). The first is mandatory under NCSE-02 and requires the weighted combination of all structural vibrational modes that mobilize more than $30 \%$ of the total mass in both horizontal directions. The second methodology is recommended by the NCSE-02 for singular structures, as the present one is. Furthermore, from the $\mathrm{TH}$ analysis relevant tolerances that can be used for NEXT operations can be extracted. Finally, the last methodology permits to design limits for $a_{H}$.

For all methodologies, the Safety Factors (SF) are computed and justified according to the Eurocode 3 [11], part of the European building standard. This code deals with the design of steel structures and uses the limit state design philosophy. Therefore, SF are defined as the ratio between the maximum stress and the admissible strength of the material: a SF close to zero implies high safety.

\section{Description of the singular structure}

As described before, one of the structure purposes is to protect the experiment against earthquakes, for which base isolation technology is assembled in the present structure: a very rigid frame is then required, see the details in Figure 12. Eight isolators are located between ground and pedestal to cut off as much as possible the NEXT structure against seismic movements.

\subsection{Lead castle}

The name "castle" for the radioactivity shielding structure, is metaphorical due to the piling of radio-pure, special lead bricks as in "dry" masonry walls, and is composed of six different piled ensembles of the blocks. Four of this ensembles are lateral, other is located on top of the vessel; all of them are contained and supported in two mobile boxes that conform the castle and that are open in just one side. The last ensemble directly lies on the pedestal top, completely closing the lead shielding.

The lead blocks have dimensions $200 \times 100 \times 50$ [mm] and are stacked and partially supported by external S275 sheets of $10[\mathrm{~mm}]$ and by internal sheets AISI-316Ti of thickness $2[\mathrm{~mm}]$. The total weight of lead is 60.6 [metric Ton], 9 [Ton] on the pedestal and 25.8 [Ton] for each half of the castle. The junction between both halfcastles is labyrinthine to prevent penetration of radiation. Finally, internal and external sheets are attached by a minimal number of perpendicular bars, since steel can offer a direct path to radiation.

The plate at the top of the castle has to support the weight of the corresponding lead ensemble. Then, it is very important to prevent a collapse in this zone against a seismic event: this top has been reinforced with AISI$316-$ Ti steel $2 \times 50 \times 50$ [mm] U-beams, see Figure 12 .

In order to prevent the access of air and gases, and consequently radiation, the castle must have a watertight enclosure in its closed configuration. Even if the junctions have been reinforced with elastic joints to guarantee the watertightness, the very stiff design helps to prevent catastrophic large displacements.

Each half-castle is supported by four self-guided wheels that roll on rails attached to the frame by HEB220 I-beams reinforced by web stiffeners, conforming a shear-buckling resistant beam, see Figure 13. These wheels are moved by two electric motors with torque 

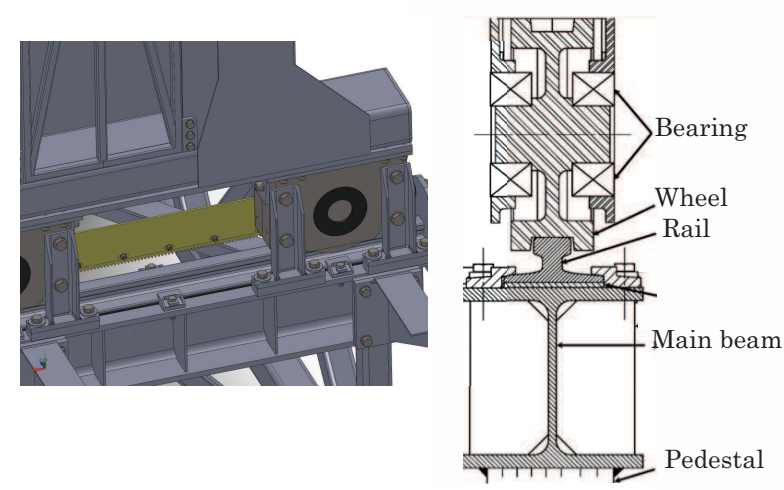

Figure 2: Three-dimensional detail (left) and drawing (right) of contact between wheel of the castle and rail of the pedestal.

limited by special clutches. During the closed operating configuration the wheels are manually fixed to the rails.

\subsection{Frame and pedestal}

The frame is a rigid truss-like structure that supports vessel and lead castle; a complete view is shown in Figure 14 along with eight seismic devices of two different types. Notice in the top of the figure the inserts for the lower lead ensemble.

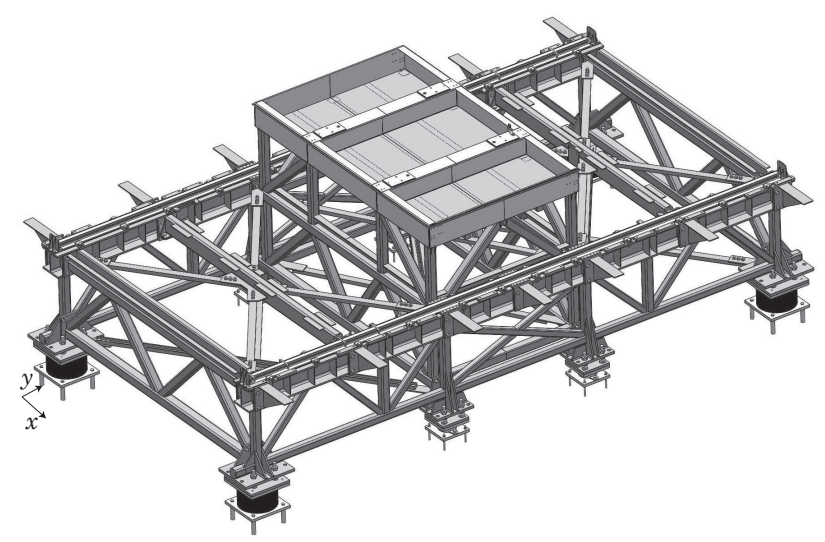

Figure 3: Tree-dimensional view of frame and pedestal, and of the eight seismic isolators: four elastomeric isolators at external corners and four pot bearings at center.

This structure is assembled from steel S-275 beams close-section with dimensions $80 \times 80 \times 8$ [mm] for the vertical members and $80 \times 80 \times 5[\mathrm{~mm}]$ for the horizontal members. Six X-frames (St. Andrew's crosses) with section UPN-65 are incorporated to the upper and lower horizontal planes of the frame to stiffen the structure. With them, the general SF and the detector horizontal displacements $d_{H}$ are reduced. On the top of the frame, two beams of close-section with dimensions $160 \times 80 \times 6$ [mm] support the motors suspended from the frame top.

Since the castle supported by the NEXT structure opens and closes and therefore adopts several positions, different load cases are studied: castle completely closed, castle completely open, one half-castle closed and the other open, etc; the two first positions are found critical. For the first case, the maximum reactions appear at the center of the structure. Therefore, four pot bearings are assembled at the frame center to take advantage of their capacity to support high vertical loads. At the four end corners, four elastomeric isolators are assembled to increase the mechanical dissipation and, consequently, to reduce $a_{H m x}$ under a seismic event. For the second case, loads are almost uniformly distributed and the maximum ground reactions are shared among the end corners and the center of the frame.

\subsection{Seismic devices}

The seismic devices dynamically isolate structures thanks to their insertion between the base of the frame and the foundation. Elastomeric isolators and free sliding pot bearings, both provided by the company [12] are assembled.

The drawing and the three-dimensional (3D) view of an elastomeric isolator model SI-S 305/115 is shown in Figure 15 top; these isolators are characterized by:

- A relatively low horizontal stiffness, to ensure the decoupling of the horizontal structural motion from the ground motion.

- A high vertical stiffness to support vertical loads without appreciable deflections.

- Appropriate energy dissipating characteristics to reduce the horizontal acceleration of the isolated structure.

The isolators are composed of steel S-275-JR plates and vulcanized elastomer layers, support a maximum vertical load of $140[\mathrm{kN}]$ with a damping factor equal or greater than $10 \%$. The attachment between ground and the pedestal is achieved by upper and lower anchor plates and chemical anchorage.

Due to their high damping, these devices modify the response spectra of the structure versus its period: using $a_{c}$ from Section 2, Figure 16 show the elastic response of a generic structure modeled as a simple linear oscillator at the free ground surface without (solid line) and with the isolator dissipation (dashed line). Two spectra are represented for $a_{H}$ and $d_{H}$ : as can be observed the 


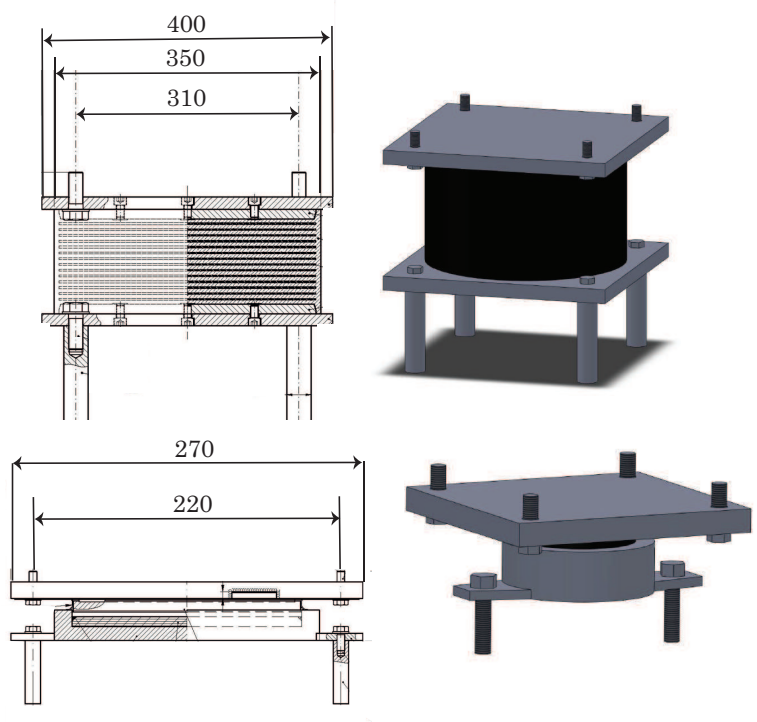

Figure 4: Drawings from [12] and three-dimensional views of elastomeric isolator (top) and sliding pot bearing (bottom). Dimensions in $[\mathrm{mm}]$.

isolators reduce both of them, although for high periods the two accelerations tend to the same value; these isolators are designed only for a particular frequency range.

The free sliding pot bearings include a rubber short cylinder reinforced by top and bottom AISI-316 stainless steel discs; this piston slides inside a steel cylindrical seat. The disc permits rotations (free horizontal displacements) and supports vertical loads with a small vertical deformation due to the pot confinement. The main characteristic of these isolators is their low friction coefficient. Figure 15 bottom shows the drawing and 3D view of a model VM 50/100/100 that resists a maximum vertical load of $500[\mathrm{kN}]$. The pot bearings are also attached by upper and lower anchor plates.

\section{Dynamic calculations}

The objective of this section is to develop dynamic calculations to optimize the design of the NEXT structure and to ensure its strength, stiffness and stability. These calculations will permit to obtain tolerances for operating devices such as flexible pipes (to flux xenon in and out the vessel), cableways for electronic equipments, etc.

All numerical calculations are performed with the FE codes COMSOL [13] and SAP2000 [14]. The first code with solid elements is used for several static calculations; for instance, Figure 6 shows SF contour-plots for two sub-models: a pot bearing (top) and a half-castle without the lead blocks (bottom). SAP2000 with beam
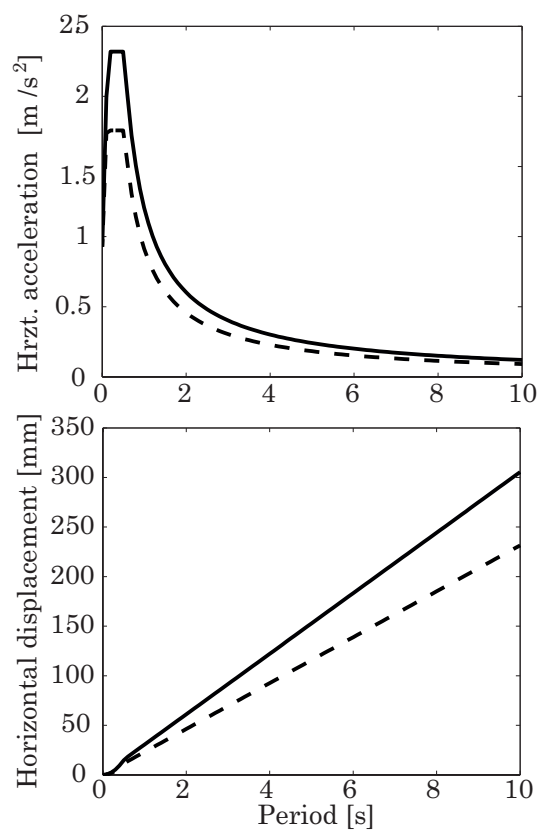

Figure 5: Effect in response spectra of increasing damping using seismic devices. Horizontal acceleration (top), displacement (bottom) vs. period. Solid line: response spectra at LSC, dashed line: modified spectra due to devices.

(for the frame) and shell elements (for the steel sheets) is used for the dynamic calculations. The non-linear behavior of the seismic devices is also simulated with a special feature of this code, a necessary aspect as reported in [15].

Additional examples of meshes for the dynamic calculations are shown in Figure 7: extruded views of the FE model for the castle (top) and the frame (bottom).

The results corresponding to the two main operation configurations (castle open and closed) are now discussed. The total static weights are shown in Table 1 , including the mass of the lead blocks, the mass of the vessel (not discretized, but its weight is taken into consideration) and live loads related wth the operation, only included in the closed configuration. According to NCSE-02, the static and seismic loads do not need to be increased, however, to increment the safety the vessel weight is augmented by a factor 1.15 due to the importance of this structural component for the experiment.

\subsection{Response Spectrum Analysis}

The maximum values of SF and $a_{H m x}, d_{H m x}$ are calculated by the RSA. To this purpose, the $a_{H}$ spectrum given in Figure 16 (solid line) is prescribed in the two 

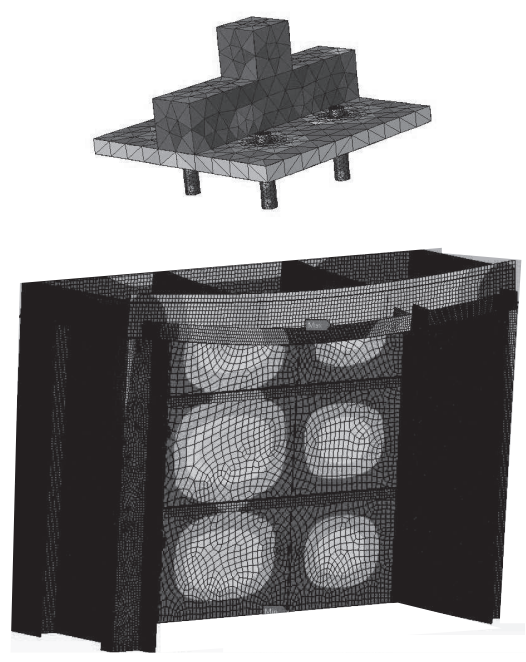

Figure 6: Isomaps of safety factors using three-dimensional finite element models of pot bearing (top) and half-castle (bottom, without lead blocks).

\begin{tabular}{|l|c|}
\hline COMPONENT & $m[\mathrm{~kg}]$ \\
\hline \hline Lead blocks & 60600 \\
Vessel & 14000 \\
Frame structure & 13200 \\
Live load (closed configuration) & 7650 \\
\hline \hline TOTAL & 95450 \\
\hline
\end{tabular}

Table 1: Summary of static gravitational loads. Mass of the vessel is increased by a factor 1.15 .

horizontal directions. This prescription is for the spectrum without seismic isolators, since as commented they are directly modeled by SAP2000.

The particular beams that are under higher loads (larger SF values) depend on the castle configuration: for the open one, the SF are lower than for the closed one, since the loads are more uniformly distributed and closer to the external supports. In any case, the maximum SF is always lower than 0.38 and, consequently, the NEXT structure readily satisfies the NCSE-02.

The calculated periods $T, a_{H m x}$ and $d_{H m x}$ are shown in Table 2 for both configurations. Only the first two modes are considered since only them move more than $30 \%$ of the total mass in both horizontal directions. The increase of periods with respect to those of the modes without isolators (not shown in this work) is due to the introduced damping; consequently, $a_{H}$ decreases and $d_{H}$ increases. The two modes listed in the table present the same period since the structure is fairly isolated in the two horizontal directions. Small differences between

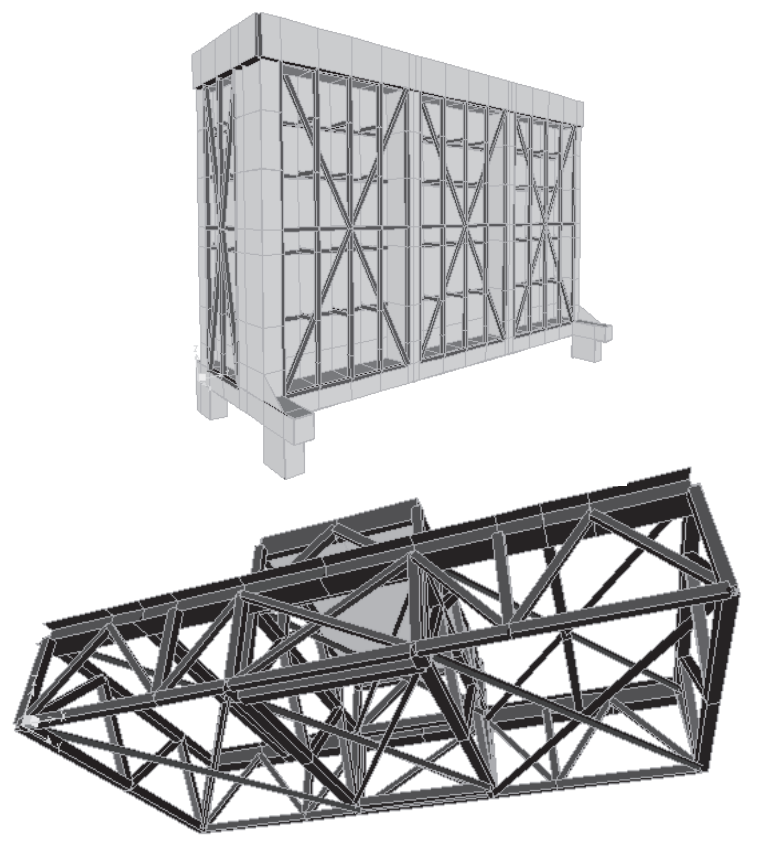

Figure 7: Three-dimensional extrude views of the finite element meshes for the castle (top) and pedestal (bottom). In both meshes, beam and shell elements are combined.

the period for closed and open configurations are observed; these differences are due to the presence of pot bearings and for the second configuration, the addition of live loads.

\begin{tabular}{|c|c|c|c|}
\hline \multicolumn{4}{|c|}{ Closed configuration } \\
\hline \hline Mode & $T[\mathrm{~s}]$ & $a_{H m x}\left[\mathrm{~m} / \mathrm{s}^{2}\right]$ & $d_{H m x}[\mathrm{~mm}]$ \\
\hline \hline 1 & 1.65 & 0.57 & 38.19 \\
\hline
\end{tabular}

\begin{tabular}{|c|c|c|c|}
\hline \multicolumn{4}{|c|}{ Open configuration } \\
\hline \hline Mode & $T[\mathrm{~s}]$ & $a_{H m x}\left[\mathrm{~m} / \mathrm{s}^{2}\right]$ & $d_{H m x}[\mathrm{~mm}]$ \\
\hline \hline 1 & 1.58 & 0.60 & 36.57 \\
\hline
\end{tabular}

Table 2: Period, maximum horizontal accelerations and displacements obtained by the Response Spectrum Analysis for open and closed castle and two vibrational modes. Only the first mode for each configuration is shown since both first and second modes are symmetric.

As commented, the spectra at Canfranc depend on the soil type, which modifies the propagation velocities of the seismic waves, and on the frame ductilities, which take into account that the structural response is not exactly in elastic or plastic regimes. In order to develop a complete study, a parametric RSA is performed considering three general types of soils (compact rock, fractured rock and compacted granular) and two ductilities: 


\begin{tabular}{|c|c|c|c|}
\hline \multicolumn{4}{|c|}{$\mu=1$} \\
\hline \hline & Type I & Type II & Type III \\
\hline \hline$a_{H m x}\left[\mathrm{~m} / \mathrm{s}^{2}\right]$ & 0.44 & 0.74 & 1.12 \\
$d_{H m x}[\mathrm{~mm}]$ & 29.7 & 50.2 & 76.0 \\
\hline \hline
\end{tabular}

\begin{tabular}{|c|c|c|c|}
\hline \multicolumn{4}{|c|}{$\mu=3$} \\
\hline \hline & Type I & Type II & Type III \\
\hline \hline$a_{H m x}\left[\mathrm{~m} / \mathrm{s}^{2}\right]$ & 0.15 & 0.25 & 0.37 \\
$d_{H m x}[\mathrm{~mm}]$ & 10 & 16.8 & 25.3 \\
\hline
\end{tabular}

Table 3: Maximum horizontal accelerations and displacements for the closed configuration of castle for soil types I, II and III, and two metal ductilities: $\mu=1$ for elastic and 3 for plastic regimes.

$\mu=1$ for the elastic regime and $\mu=3$ for the plastic one. For simplicity, this parametric study is reported only for the more detrimental closed configuration.

Table 3 shows the maximum $a_{H}$ and $d_{H}$ for the six combinations. Both magnitudes increase with the soil type and substantially decrease with plasticity. For soil type III and $\mu=1, a_{H m x}$ exceeds the allowed $1\left[\mathrm{~m} / \mathrm{s}^{2}\right]$, however, this soil is not present at Canfranc according to the geotechnical analyses provided by the LSC.

In conclusion, the RSA study reveals that the structure satisfies the NCSE-02 and in addition, that $a_{H m x}$ is low enough and that $d_{H m x}$ is approximately 40 [mm]. This displacement is taken into account to design a gap between the NEXT frame and a static work platform (not shown in Figure 12).

\subsection{Time-History Analyses}

The main purposes of the TH analyses are similar to those of the previous subsection although now under a more refined calculation.

\begin{tabular}{|c|c|c|c|}
\hline Earth. & Date & Place & Magnitude \\
\hline E1 & May 11, 1976 & Friuli & 4.9 \\
E2 & Sept 16,1977 & Friuli & 5.4 \\
E3 & May 24, 1979 & Montenegro & 6.2 \\
E4 & Sept 11,1976 & Friuli & 5.5 \\
E5 & Sept 15, 1976 & Friuli & 6.0 \\
\hline
\end{tabular}

Table 4: Five real earthquakes used for the time-history analysis with their Richter scale magnitudes in $[\mathrm{Mw}]$.

In order to develop these analyses, five real and past earthquakes are applied along both horizontal directions, as recommended by NCSE-02. These earthquakes, see Table 4, are denoted by E1 to E5 and are chosen to represent a wide range of seismic events: E1, $\mathrm{E} 2, \mathrm{E} 3$ happened near to the fault $(<10[\mathrm{~km}])$ and $\mathrm{E} 4$,
E5 far from the fault $(>10[\mathrm{~km}])$. The maximum acceleration and duration of these events are normalized to $a_{c}=0.095 \mathrm{~g}$ and $t=25[\mathrm{~s}]$, according to the standard.

Figure 19 shows the accelerations in both horizontal directions versus time at the vessel support for the five earthquakes, without (left column) and with (right column) seismic devices. Only the closed configuration is reported since it is the operating mode and the probability that a seismic event occurs during it is much higher.

In the left column, it is evident that $a_{x}>>a_{y}$ due to the lack of symmetry of the structure: the stiffness of the frame is much higher in the short direction than in the long one, see Figure 14. E2 produces the maximum acceleration since it introduces a large amount of energy in a few seconds. For all earthquakes, $a_{x}$ exceeds the limit value $1\left[\mathrm{~m} / \mathrm{s}^{2}\right]$, this being the main reason why seismic devices are incorporated into the structure. The decrease of $a_{H}$ is evident as shown in the right column and furthermore, with this incorporation the accelerations in both directions become practically equal since the structure is isolated by symmetric devices and then achieves the same period of vibration: the symmetry improves the operation of the experiment.

Another important task achieved by the $\mathrm{TH}$ is the contribution to the sizing and design of pipes and cableways. For this purpose, the relative displacements between the tip of the vessel and the internal sheet of the lead castle are calculated: both parts vibrate together but due to the structural elasticity some reciprocal movement appears. It is important to quantify these displacements since, to minimize the amount of expensive lead, the castle must be placed as close as possible to the vessel. Figure 20 shows the displacements for the five earthquakes and the closed configuration. As can be appreciated, the results without isolators (dashed line) are abrupt for all earthquakes with a maximum of $3.5[\mathrm{~mm}]$ : this relative high appears because the structural horizontal movements are decoupled. In contrast, with the inclusion of isolators (solid line) the structure can be compared to a rigid solid suspended by springs and dampers. Therefore, the relative displacements are damped with a practically negligible $0.5[\mathrm{~mm}]$ and with no significant peaks.

\section{Reliability-based design}

The objective of this section is to verify that $a_{H m x}$ satisfies the operating requirement at the detector support. For this purpose, the most advanced technique is the reliability-based approach [8], for which the Probability of Failure (POF) is defined as the probability of a system failing to respond to a demand, in particular 

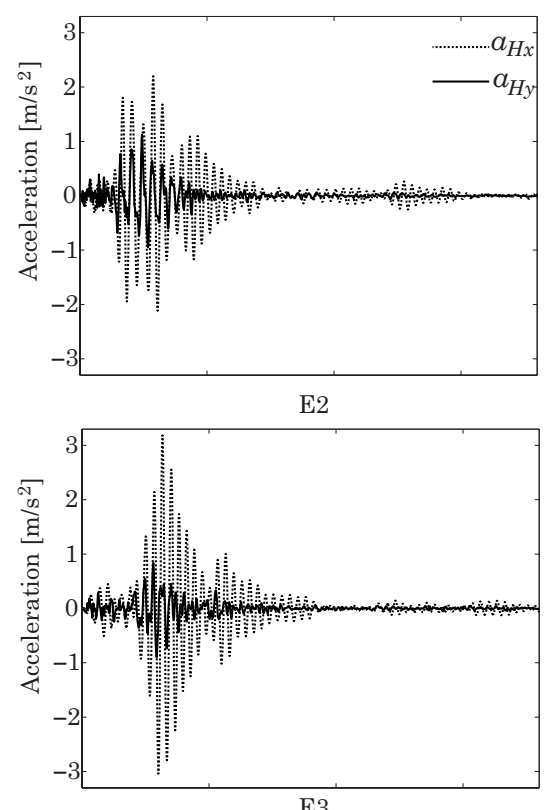

E3
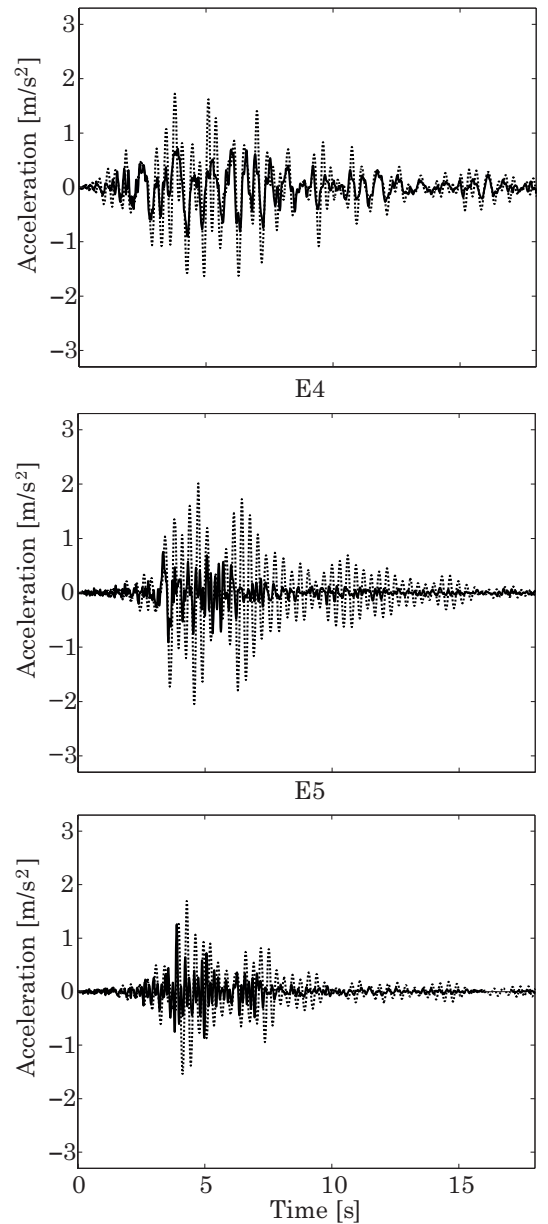

E1
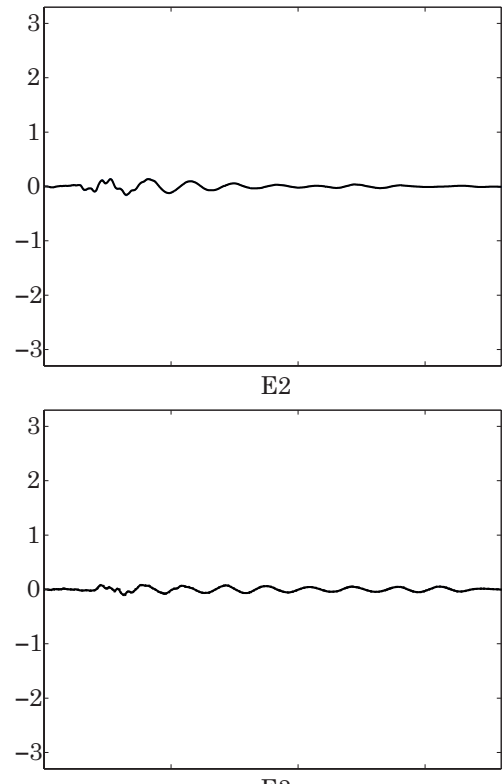

E3

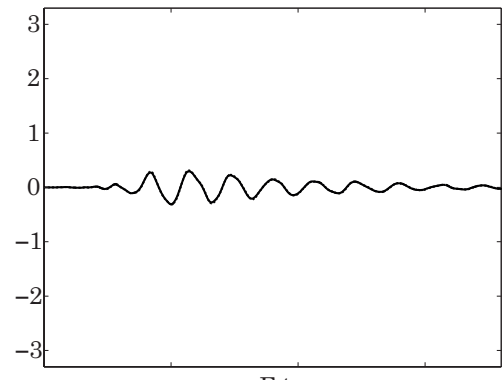

E4
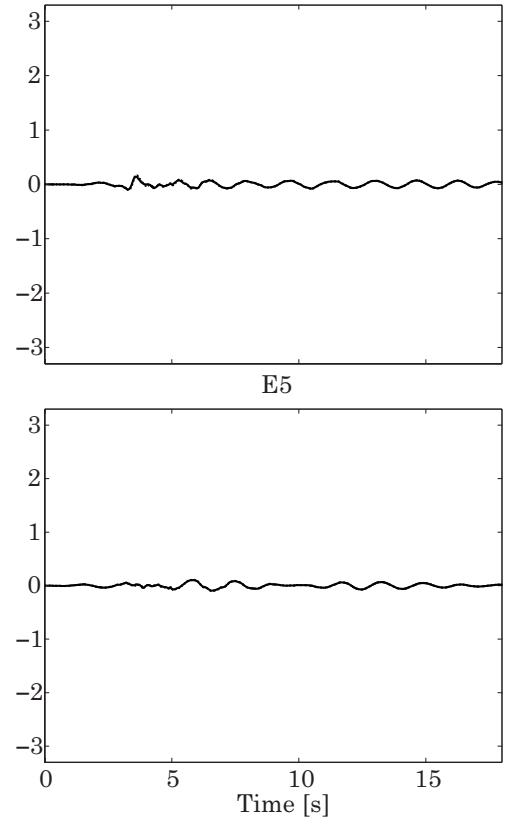

Figure 8: Acceleration in the horizontal directions (longitudinal and transversal) versus time at the vessel support for the five earthquakes given in Table 4. Left column without and right column including seismic devices. 


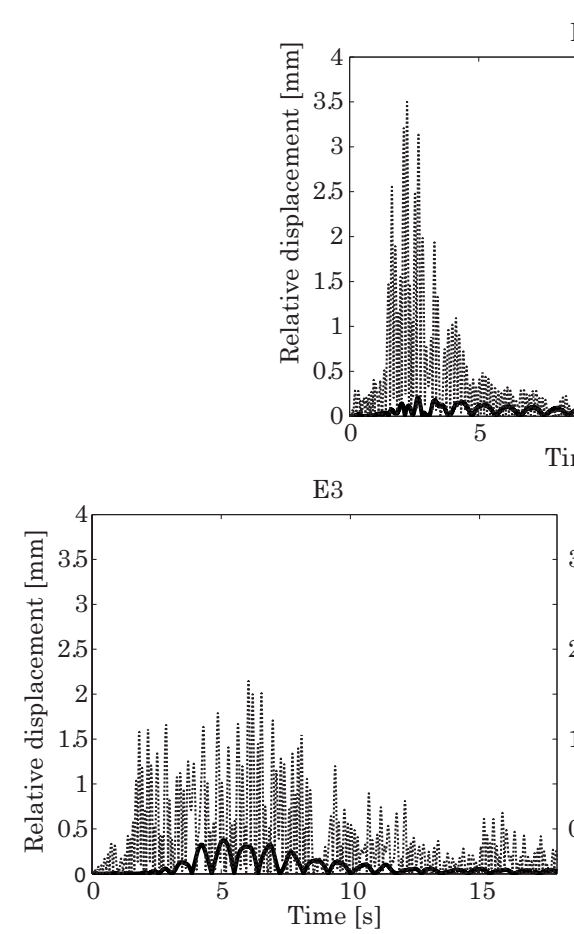

E1
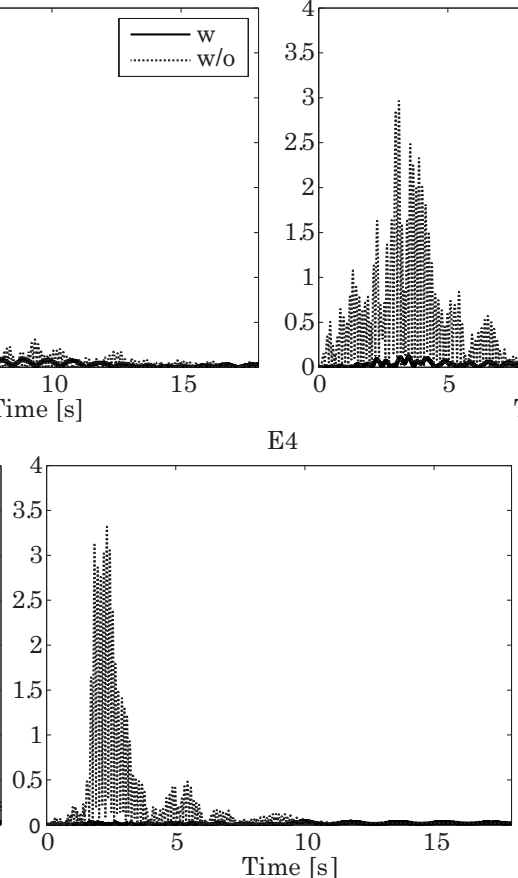

E2

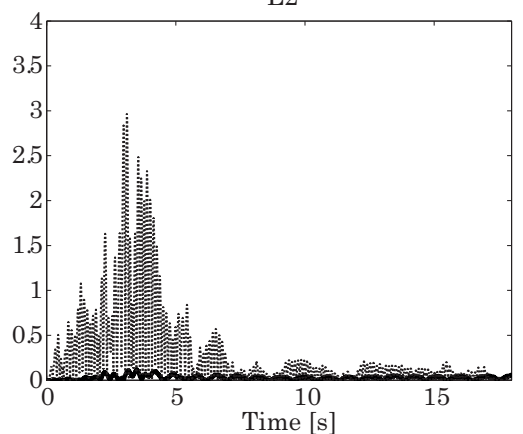

E5

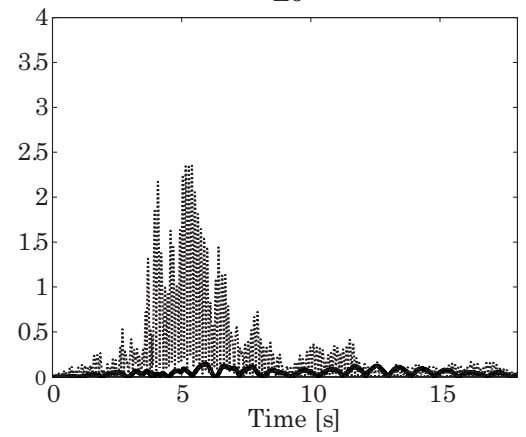

Figure 9: Relative displacement between vessel tip and lead castle internal wall for the five earthquakes given in Table 4, with (w) and without (w/o) seismic devices.

the probability of exceeding the defined acceleration. In the present work, the demand is represented by the random earthquakes and the equipment failure due to structure accelerations, therefore, the POF is mathematically given by:

$$
\mathrm{POF}=\mathcal{P}\left(a_{H m x}<1\right)
$$

Obviously, $a_{H m x}$ depends on the stiffness of NEXT structure and the constitutive parameters of the seismic devices (denoted by the vector $\mathbf{x}$ ). In addition, it is a random variable due to the intrinsic randomness of the earthquakes. Therefore, the POF can also mathematically be represented as a probabilistic variable given by:

$$
\mathrm{POF}=\int_{g(\mathbf{x})<0} f_{x}(\mathbf{x}) \mathrm{d} \mathbf{x}
$$

where $g(\mathbf{x})=a_{H m x}-1<0$ denotes the limit state function and $f_{x}(\mathbf{x})$ is the joint probability distribution function. This function cannot be represented by any analytical expression, and for this reason it is evaluated with numerical methods.

The Monte Carlo method [16] permits to approximately evaluate the POF, with a random sample of $N$ earthquakes generated with a seismogram simulator [17], see the flow chart of Figure 21. This figure shows the procedure used to perform the RBD. First a significant sample of 1,000 earthquakes are simulated (bottom-left); then, these earthquakes are prescribed in the SAP2000 link element (top-left). The FE code is executed and for each case, the maximum accelerations at the vessel support are calculated (top-right); Finally, a histogram is plot representing all the obtained maximum accelerations (bottom-right).

Again all earthquakes are normalized to $a_{c}=0.095 \mathrm{~g}$ and $t=25[\mathrm{~s}]$ and are prescribed at the eight isolators; then $a_{H m x}$ is numerically calculated with the FE model at the vessel support. Finally, the POF numerically becomes:

$$
\mathrm{POF}=\frac{N_{f}}{N}
$$

where $N_{f}$ is the number of failures. For a proper calculation of the POF and according to [18], $N$ can indirectly be calculated by:

$$
N \approx \frac{1}{\mathrm{POF}}
$$

Using the estimation given by (4) and considering that a reasonable POF for the NEXT experiment is $0.1 \%$, the size of the sample must be $N=1000$. 


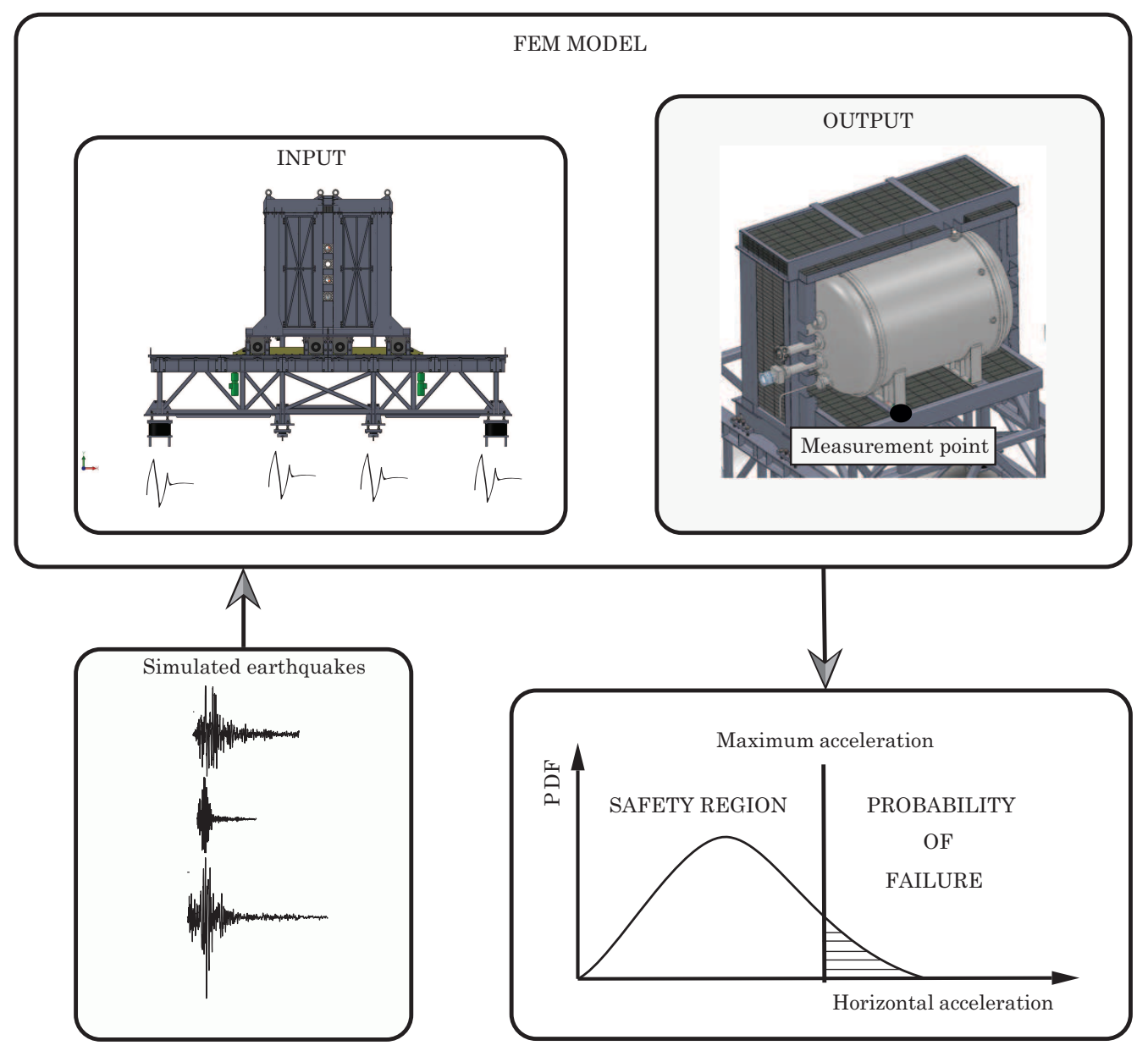

Figure 10: Flow chart of the reliability-based approach: earthquakes simulated according to the Spanish standard and applied at the eight isolators. The maximum horizontal acceleration at a vessel support (black point top-right) is calculated. Reliability approach based on the probability of failure conducted to ensure that the maximum horizontal acceleration is in the safety region (bottom-right).

The flow chart process of Figure 21 is repeated increasing the stiffness of the rigid frame until approximately POF $\leq 0.1 \%$ is obtained. Figure 22 shows a histogram from RBD that represents the number of simulated earthquakes that provoke a certain $a_{H m x}$ in the final NEXT structure. This histogram is equivalent to the conceptual Probability Distribution Function (PDF) of the Figure 21 bottom-right. The admissible $a_{H m x}$ is highlighted by a thick vertical line and from the histogram and the final probability is calculated by (3) to give a moderate POF $=0.125 \%$. The ideal situation of a distribution centered on a value close to zero is observed, however, a small number of earthquakes with $a_{H m x}>1$ appear. The use of isolators moves the histogram curve to the left and allows to find an optimal design of the structure.

\section{Conclusions}

The calculation of an optimized and seismic-resistant and singular metallic structure to be used in High Energy Physics has been described. This singular structure has to satisfy two requirements: i) ensure the radiopurity of the experiment and ii) horizontal acceleration lower than $1\left[\mathrm{~m} / \mathrm{s}^{2}\right]$. For the first condition, a mobile structure with lead blocks (called "castle") is designed and it is supported by a very rigid frame to limit the displacements that can become catastrophic. For the second condition, eight seismic isolators (elastomerics and "pot" bearings) are mounted between frame and ground.

Three dynamic finite element calculations are developed in order to satisfy the Spanish seismic standard, to ensure the dynamic requirements of the experiment and to optimize the rigid frame. In the first calculation, a response spectra analysis is performed: it is shown 


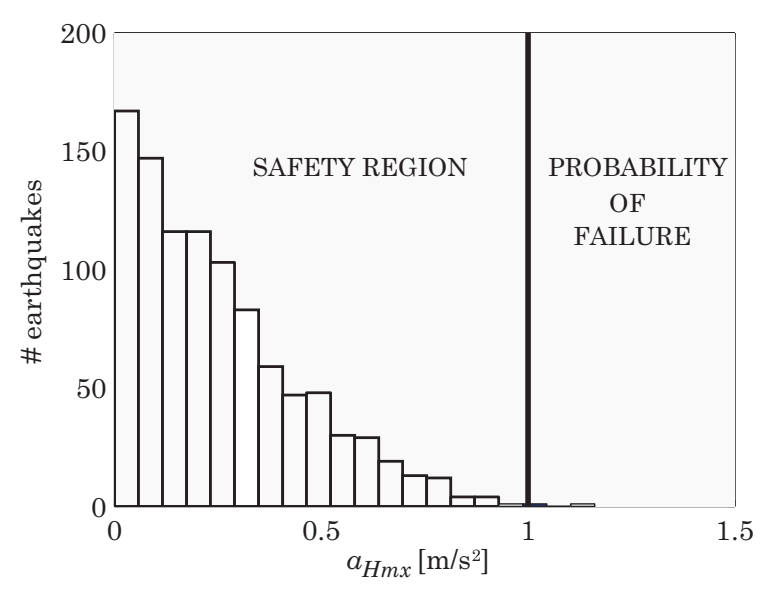

Figure 11: Calculated histogram representing the number of earthquakes (total of 1,000) that reach a certain maximum horizontal acceleration at the vessel support of the NEXT structure.

that all the safety factors are substantially lower than 1 , implying safety. For the second, five real earthquakes, normalized according to the Spanish standard are simulated to check the horizontal acceleration. In addition, the displacement of pipes and electronic connections of the vessel (a neutrino detector enclosed and shielded by a mobile structure containing radio-pure lead) are also appraised. The third calculation uses a reliability-based approach to optimize the design of the rigid frame with a sample of 1,000 simulated and scaled earthquakes.

The present methodology is applicable to the structural design of future experiments under similar requirements.

\section{References}

[1] V. Álvarez, et al., Next-100 technical design report (TDR).executive summary, Journal of Instrumentation 7 (2012) T06001.

[2] NCSE-02, Normas de construcción sismorresistente: parte general y edificació, Ministerio de Fomento, Spain.

[3] J. Kelly, Base isolation: linear theory and design, Earthq Spectra 6 (1997) 223-244.

[4] C. Alhan, H. Gavin, Reliability of base isolation for the protection of critical equipment from earthquake hazards, Engineering Structures 27 (2005) 1435-49.

[5] H. Iemura, T. Taghikhany, S. Jain, Optimum design of resilient sliding isolation system for seismic protection of equipments, Bulletin of Earthquake Engineering 5 (2007) 85-103.

[6] M. Hamidi, M. E. Naggar, On the performance of scf in seismic isolation of the interior equipment of buildings, Earthquake Eng Struct Dynam 36 (2007) 1581-604.

[7] G. Yao, W.-C. Huang, Performance of a guideway seismic isolator with magnetic springs for precision machinery, Earthquake Eng Struct Dynam 5 (2009) 181-203.

[8] G. Jia, I. Gidaris, A. Taflanidis, G. Mavroeidis, Reliability-based assessment/design of floor isolation systems, Engineering Structures 78 (2014) 1676-84.
[9] L.-Y. Lu, G.-L. Lin, Predictive control of smart isolation system for precision equipment subjected to near-fault earthquakes, Engineering Structures 30 (2008) 3045-3064.

[10] H. Gavin, A. Zaicenco, Performance and reliability of semiactive equipment isolation, J Sound Vib 306 (2007) 74-90.

[11] Eurocode 3, Design of steel structures, The European Standard.

[12] Fip industriale leading technologies, http://www.fipindustriale.it, accessed: 2010-0909.

[13] COMSOL, COMSOL multiphysics 3.3a documentation.

[14] C. Computers and Structures Inc., Sap2000 v10 integrated finite element analysis and design of structures, CSI-Berkeley.

[15] M. Dolce, D. Cardone, F. Croatto, Frictional behavior of steelPTFE interfaces for seismic isolation, Bulletin of Earthquake Engineering 3 (2005) 75-99.

[16] R. Palma, G. Rus, R. Gallego, Probabilistic inverse problem and system uncertainties for damage detection in piezoelectrics, Mechanics of Materials 3 (2005) 1000-1016.

[17] D. Boore, Simulation of ground motion using the stochastic method, Pure Appl Geophys 160 (2003) 635-676.

[18] A. Haldar, S. Mahadevan, Probability, Reliability, and Statistical Methods in Engineering Desing, John Wiley \& Sons, Inc., 2000. 

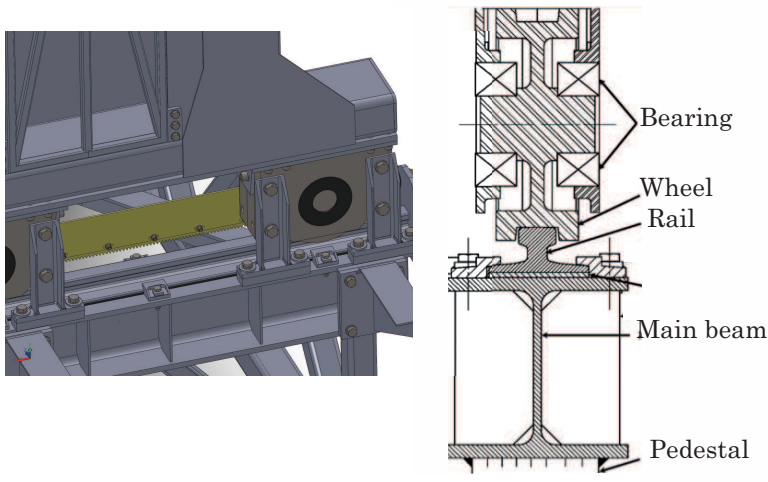

Figure 13: Three-dimensional detail (left) and drawing (right) of contact between wheel of the castle and rail of the pedestal.

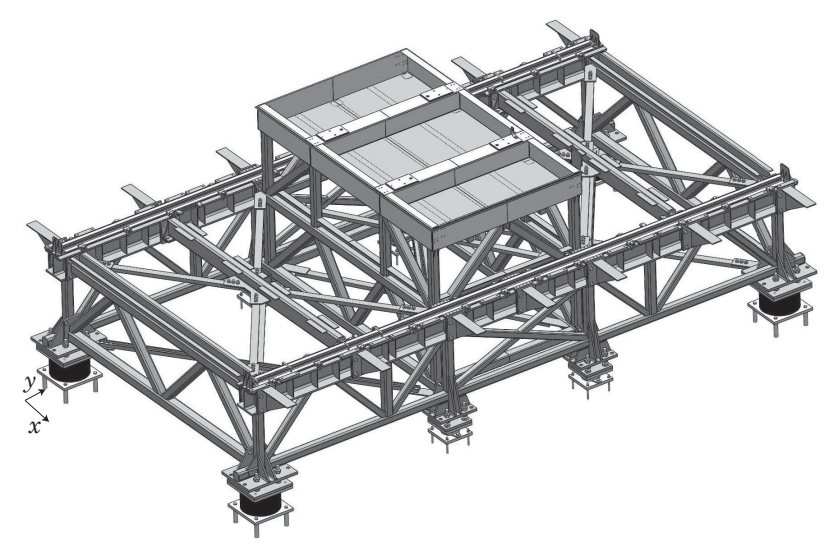

Figure 14: Tree-dimensional view of frame and pedestal, and of the eight seismic isolators: four elastomeric isolators at external corners and four pot bearings at center.

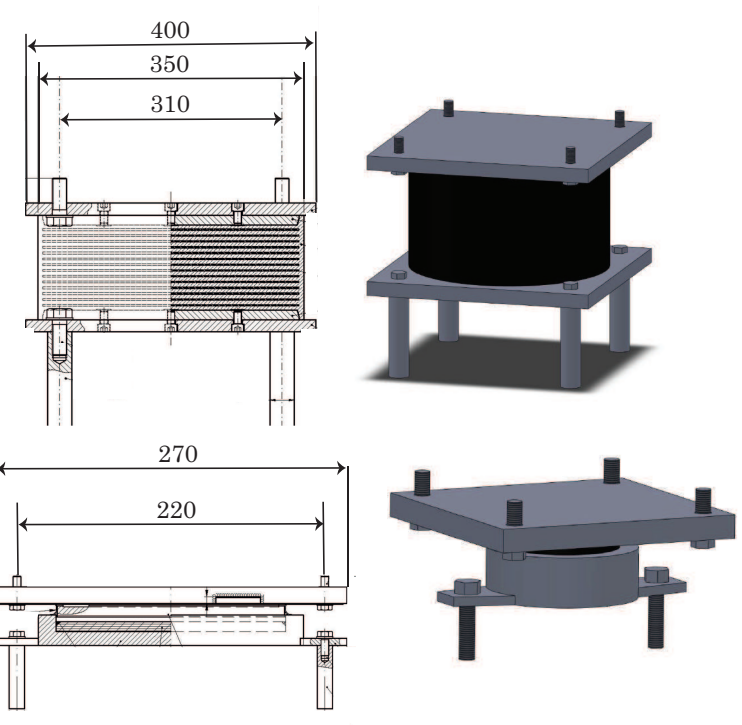

Figure 15: Drawings from [12] and three-dimensional views of elastomeric isolator (top) and sliding pot bearing (bottom). Dimensions in $[\mathrm{mm}]$.
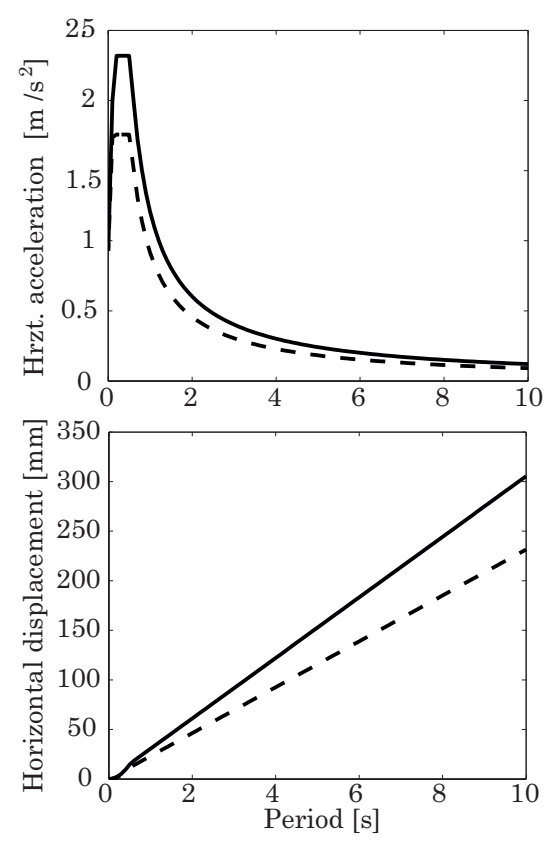

Figure 16: Effect in response spectra of increasing damping using seismic devices. Horizontal acceleration (top), displacement (bottom) vs. period. Solid line: response spectra at LSC, dashed line: modified spectra due to devices. 


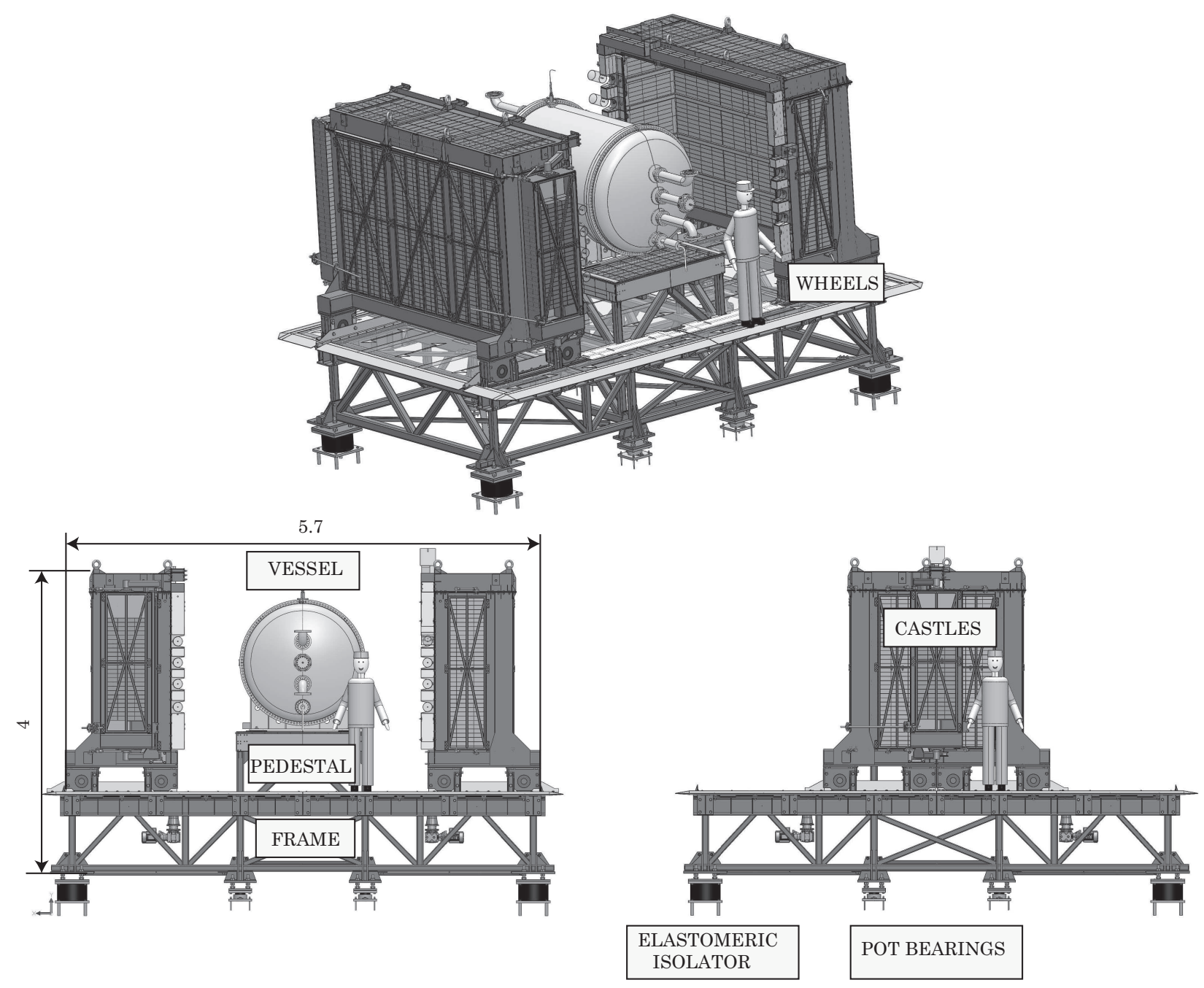

Figure 12: Three-dimensional view of the singular NEXT structure (top). Front views of open (bottom-left, for maintenance) and closed (bottomright, for operation) configurations. Structure composed of frame, pedestal, lead castle, vessel and seismic isolators. Dimensions in [m]. 


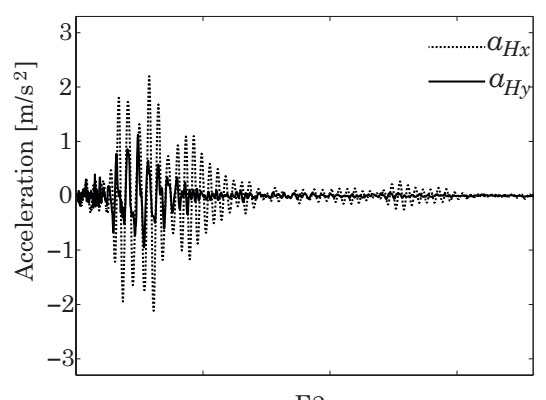

E2

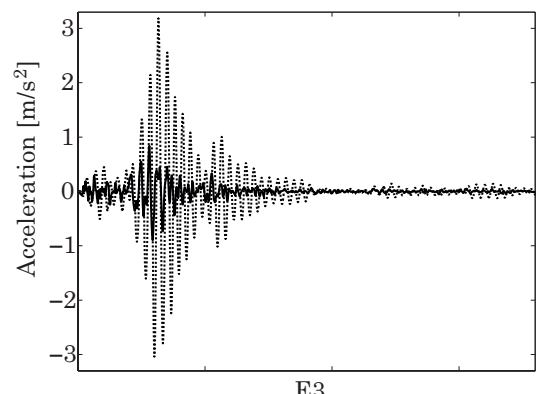

E3
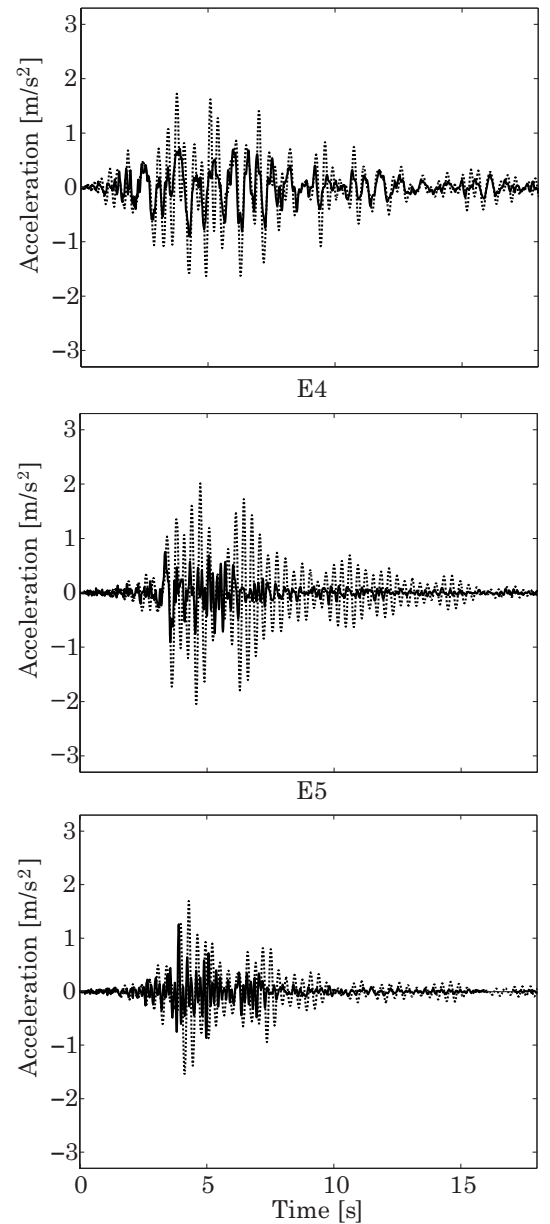

E1
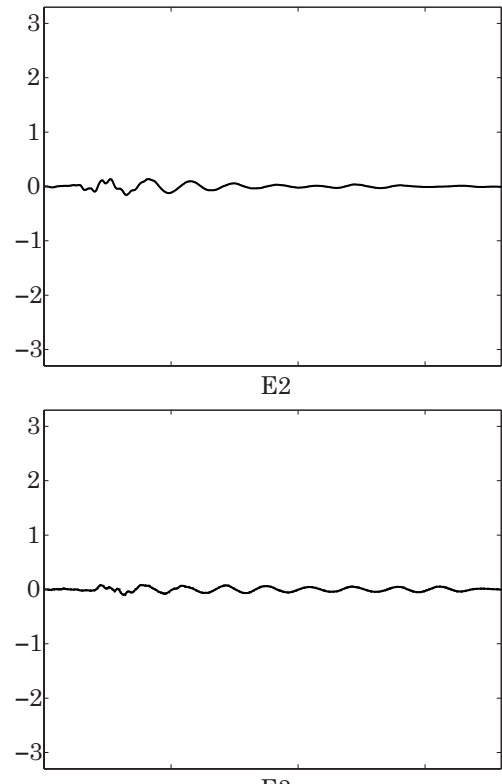

E3

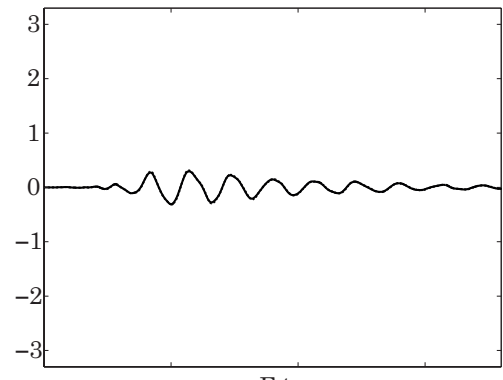

E4
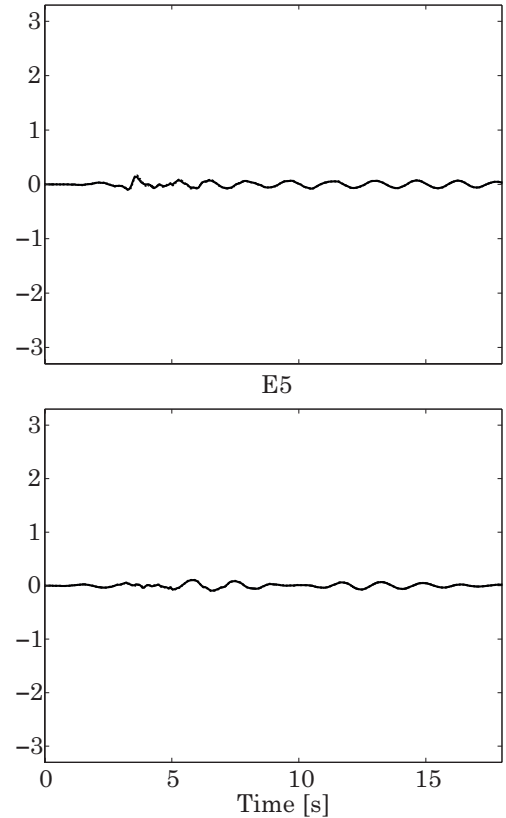

Figure 19: Acceleration in the horizontal directions (longitudinal and transversal) versus time at the vessel support for the five earthquakes given in Table 4. Left column without and right column including seismic devices. 

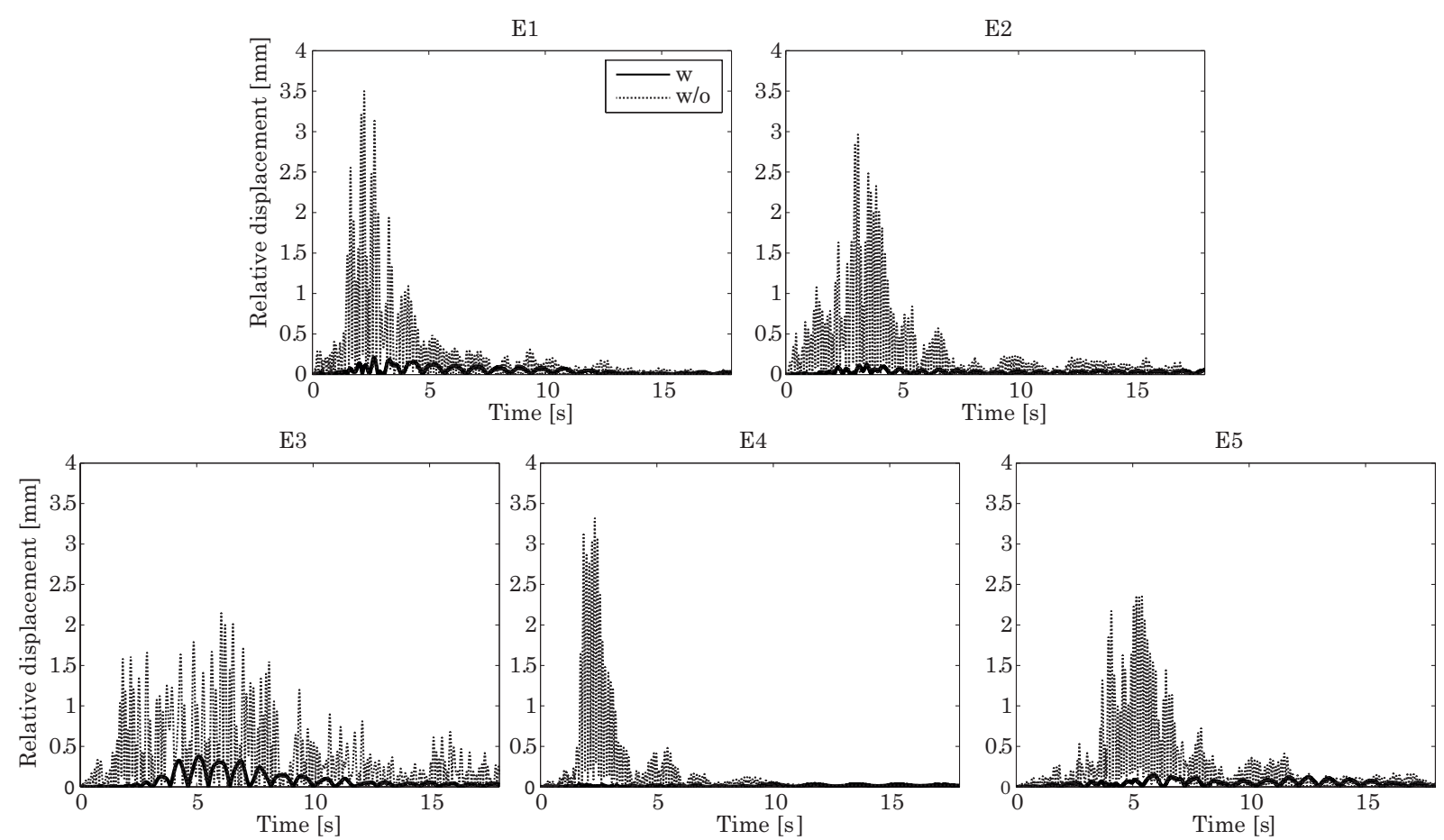

Figure 20: Relative displacement between vessel tip and lead castle internal wall for the five earthquakes given in Table 4, with (w) and without (w/o) seismic devices. 


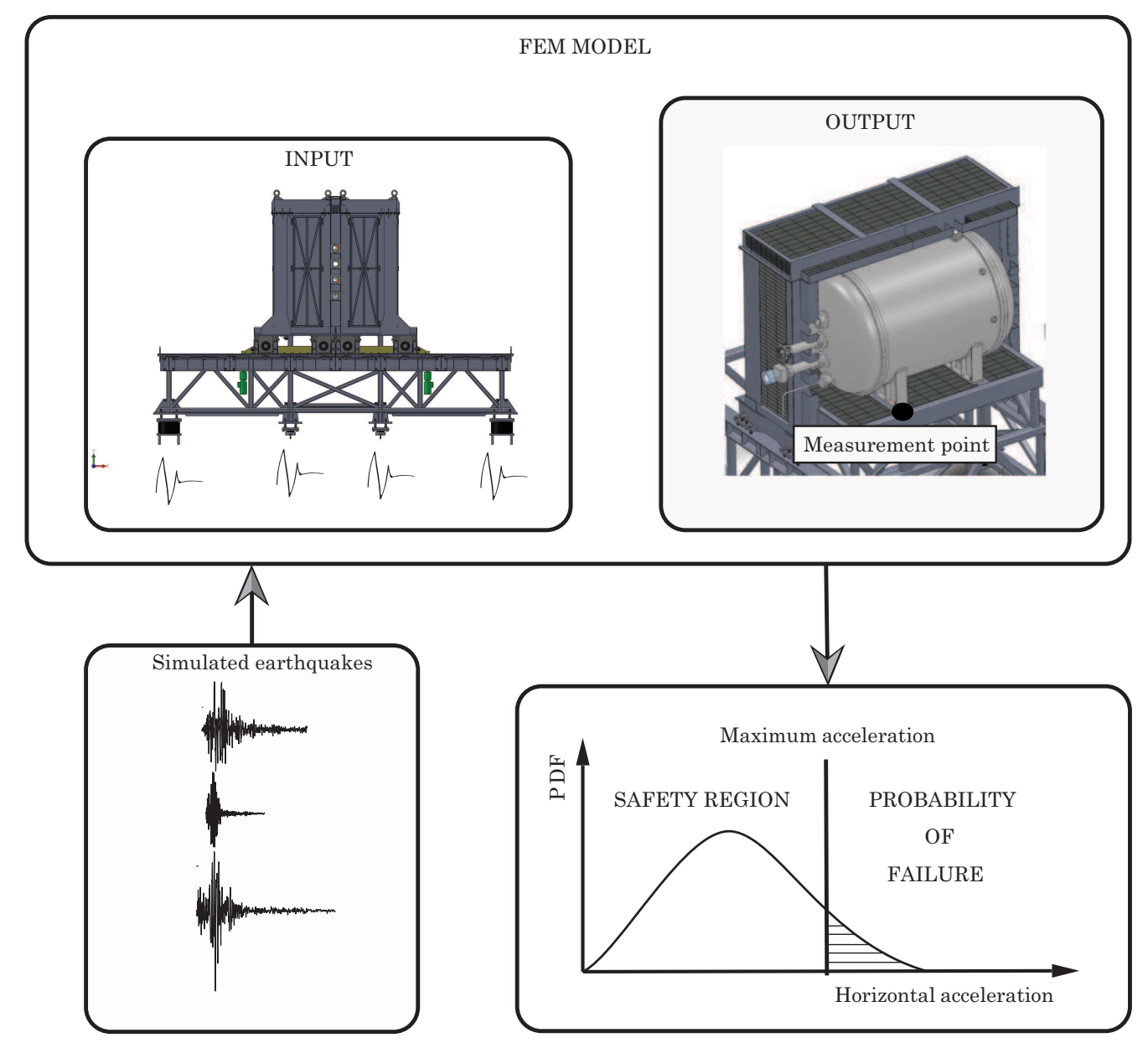

Figure 21: Flow chart of the reliability-based approach: earthquakes simulated according to the Spanish standard and applied at the eight isolators. The maximum horizontal acceleration at a vessel support (black point top-right) is calculated. Reliability approach based on the probability of failure conducted to ensure that the maximum horizontal acceleration is in the safety region (bottom-right).

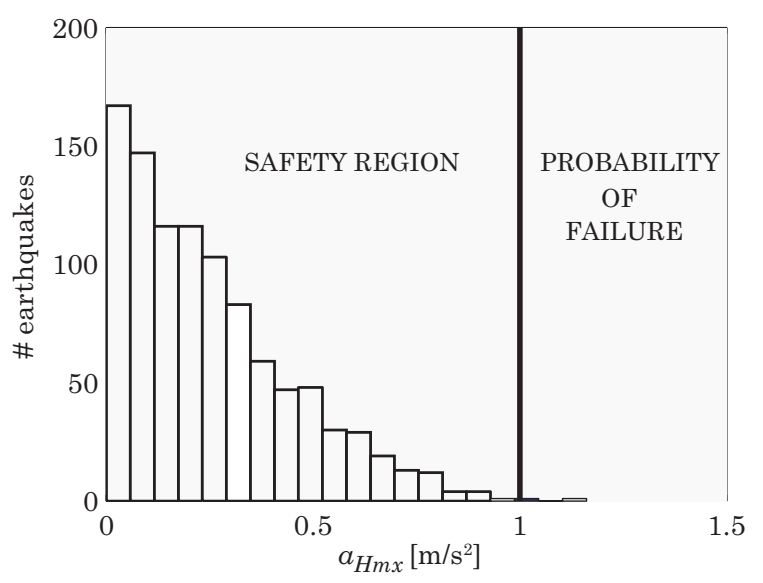

Figure 22: Calculated histogram representing the number of earthquakes (total of 1,000) that reach a certain maximum horizontal acceleration at the vessel support of the NEXT structure. 